\title{
EXPERIMENTAL STUDY ON THE INFLUENCE OF AZO-TUBERCULIN UPON GUINEA-PIGS INFECTED WITH TUBERCLE BACILLI \\ PART II. ISOLATION OF THE O-AMINOPHENOL AZO-TUBERCURIN DERIVATIVE FROM “SAUTON'S SYNTHETIC-MEDIUM OLD TUBERCULIN"
}

\author{
By Ryo ITO AND SABURo KOSHIMURA \\ The Laboratories of the Pharmacological and Pharmaceutical Department and \\ the Chemical Depariment of the Research Institute of Tuberculosis, \\ Kanazawa Medical University, Kanazawa
}

The preceding paper (1) of this series includes reports on the biological properties of $o$-aminophenol azo-tuberculin derivative prepared by coupling purified tuberculin (Maschmann) with diazotized $o$-aminophenol.

Due to the lamentable circumstances in Japan, which oppose a repetition of azotization experiments with purified tuberculin on a large scale, studies were being continued in our laboratory in an effort to find more simple method for obtaining $o$-aminophenol azo-tuberculin.

The present communication records the newly devised method for preparing highly active $o$-aminophenol azo-tuberculin derivative from "Sauton's synthetic-medium Old Tuberculin" itself.

\section{Isolation of $o$-Aminophenol Azo-Tuberculin Derivatives}

a) Preparation of a Sauton's Synthetic-Medium Old Tuberculin :

$5,600 \mathrm{cc}$ of Sauton's synthetic medium* was distributed in 28 half-litre bottles, $200 \mathrm{cc}$ to a bottle, and all bottles of medium ware planted at a time with the human type of tubercle bacillus, strain $\mathrm{H}_{2}$, in the usual manner. After incubation at $37^{\circ} \mathrm{C}$ for ten weeks, the cultures were shaken and heated in a steam sterilizer at $100^{\circ} \mathrm{C}$ for one hour. The bacilli were filtered from the culture liquid through filter paper. The total volume of filtrate was $3,850 \mathrm{cc}$.

The filtrate was then concentrated on the water bath to a volume of $770 \mathrm{cc}$, that is, to one-fifth the original volume of the culture filtrate. After passing through Seitz E. K. filter, $170 \mathrm{cc}$ of this concentrated liquid ${ }^{* *}$ was withdrawn and preserved

* The formula of the Sauton's synthetic medium:

Asparazine

Citric acid............................................. 2.0

Potassium monohydrogen phosphate......... 0.5

Magnesium, sulfate ................................. 0.5

Ferric ammonium citrate ....................... 0.05

Glycerol............................................ 60.0

Distilled water .......................................1000,0

(Adjusted to $\mathrm{pH} 7.2$ with ammoniac.)

* The concentraced liquid was called SOT, meaning “Sauton's synthetic-medium Old Tuberculin", to fit into a scheme of abbreviated nomenclature. 
for control purposes throughout the biological experiments.

The remaining $600 \mathrm{cc}$ of the Sauton's synthetic-medium Old Tuberculin (SOT) was: used for the experiments concerned with the correlation between azotization grade. and tuberculin activity.

b) Azotization Experiments of Sauton's Synthetic-Medium Old Tuberculin (SOT) with $o$-Aminophenol Diazonium Chloride:

The remaining $600 \mathrm{cc}$ of SOT was divided into six equal lots of $100 \mathrm{cc}$ each, designated as Lots I to VI. To six lots of SOT, six different amounts of $o$-aminophenol diazonium chloride were added respectively, as indicated in Table 1. As further manipulations were the same in the all lots, so only the procedures empioyed for the isolation of $o$-aminophenol azo-tuberculin from the Lot $\mathrm{V}$ will be described below in detail :

$1.0 \mathrm{~g}$ of $o$-aminophenol base was dissolved in $22 \mathrm{cc}$ of $\mathrm{N} / 1 \mathrm{HCl}$ and diazotized with $0.63 \mathrm{~g}$ of sodium nitrite dissolved in $8 \mathrm{cc}$ distilled water, at a temperature of $0^{\circ} \sim 5^{\circ} \mathrm{C}$ with starch iodide paper as indicator. After the solution showed no excess of nitrite, it was diluted with ice water to a volume of $80 \mathrm{cc}$ and added to a cold mixture of $100 \mathrm{cc}$ SOT (Lot V) and $30 \mathrm{cc} \mathrm{N} / 1 \mathrm{NaOH}$. The mixture, chiiled with ice, was kept weakly alkaline to litmus by adding about $10 \mathrm{cc} \mathrm{N}_{/} 1 \mathrm{NaOH}$.

After standing oyernight at ice box temperature, the mixture was carefully acidified with $\mathrm{N} / 1 \mathrm{HCl}$ to a point of maximum precipitation, the $\mathrm{pH}$ of the solution being 4.8. The highly colored precipitate of $o$-aminophenol azo-tuberculin (=O.A.-azotuberculin) was removed by centrifugation.

The precipitate, after washing three times with $0.85 \% \mathrm{NaCl}$ solution (using $50 \mathrm{cc}$ in each time), we call "crude O.A.-azo-tuberculin." The three washings were combined with the supernatant.

(i) Purification of crucle O.A.-azo-tuberculin derivative :

The crude O.A.-azo-tuberculin was dissolved in $20 \mathrm{cc}$ of salt solution by adding the minimal amount of $\mathrm{N} / 10 \mathrm{NaOH}$, some insoluble material centrifuged out, and from the dark brown supernatant the active substance (that is, O.A.azo-tuberculin) was reprecipitated by acidifying to $\mathrm{pH} 5.0$ with $\mathrm{N} / 10 \mathrm{HCl}$. Solution and reprecipitation were repeated more two times. The precipitate was then dissolved in $15 \mathrm{cc}$ of saline with the aid of a little $\mathrm{N} 10 \mathrm{NaOH}$, and to the solution, with stirring, three volumes of cold $60 \%$ alcohol was added and subsequently enough $\mathrm{N} / 10 \mathrm{HCl}$ to flocculate the material.

After centrifugation, the precipitate obtained was redissolved in $20 \mathrm{cc}$ salt solution with a small amount of $\mathrm{N} / 10 \mathrm{NaOH}$, and the solution was dialyzed, in fish bladder membrane, against running water for about 24 hours. From the solution left in the dialyzing sac O.A.-azo-tuberculin was precipitated by the addition of $\mathrm{N}_{/} 10 \mathrm{HCl}$, washed with distilled water and finally dried in a vacuum desiccator.

About $142 \mathrm{mg}$ of O.A.-azo-tuberculin derivative was obtained in the form of a 
deeply reddish-brown, amorphous substance.

(ii) The residuai part:

A mixture of the supernate and the three washings was adjusted to $\mathrm{pH} 5.4$, concentrated on the water bath to the original volume of SOT $(100 \mathrm{cc})$ ard passed through Seitz E. K. filter. The brownish-red colored liquor thus obtained, we: call "residual part."

Table 1. The degree of coupling the SOT with diazotized $o$-aminophenol and the yields of O.A-azo-tuberculin derivatives.

\begin{tabular}{c|c|c|c|c|c|c}
\hline No. of SOT-lot & I & II & II & IV & V & I \\
\hline $\begin{array}{c}\text { o-Aminophenol used for azo- } \\
\text { tization (in mg) }\end{array}$ & 20 & 100 & 400 & 800 & 1000 & 1600 \\
\hline $\begin{array}{c}\text { Yields of O.A.-azo-tuber- } \\
\text { culin derivatives (in mg) }\end{array}$ & $\begin{array}{c}\text { less than } \\
4\end{array}$ & 9 & 30 & 49 & 142 & 83 \\
\hline
\end{tabular}

Thus, the yield of O.A.-azo-tuberculin derivatives was the greatest in the azotization experiment of No. V-lot (142 mg) followed respectively by No. VI-lot $(83 \mathrm{mg})$, No. IV-lot ( $49 \mathrm{mg})$, No. III-lot (30 mg), No. II-lot $(9 \mathrm{mg}$ ) and No. I-lot (less than $4 \mathrm{mg}$ ).

It will be noted with exception of the yield from lot VI in Table 1 that the yield: of O.A.-azo-tuberculin derivatives rises in proportion to the quantity of $o$-aminophenol used for azotization.

\section{Biological Properties}

1. Skin Test. -

A. Experiments with O.A.-azo-tuberculin preparations.

Five O.A.-azo-tuberculin preparations, Nos. II to VI, were tested for their skin-reacting potency, using the original Sauton's medium Old Tuberculin as a standard of comparison.

\section{Methods}

1) Substance used:

(i) O.A.-azo-tuberculin preparations, Nos. II, III, IV, V, and VI.

$0.5 \mathrm{mg}$ of O.A.-azo-tuberculin preparation to be tested was dissolved in $5.0 \mathrm{cc}$ of sterile $0.85 \% \mathrm{NaCl}$ solution with the aid of the minimal amount of $\mathrm{N} / 10 \mathrm{NaOH}$. (Thus, $0.1 \mathrm{cc}$ of this solution contains $0.1 \mathrm{mg}$ of O.A.-Azo-T. "S"*.) This original solution was diluted with sterile salt solution serially, i. e., $0.01 \mathrm{mg}$ in $0.1 \mathrm{cc}, 0.001 \mathrm{mg}$ in $0.1 \mathrm{cc}, 0.000,1 \mathrm{mg}$ in $0.1 \mathrm{cc}$, $0.000, \mathrm{c} 5 \mathrm{mg}$ in $0.1 \mathrm{cc}$ and $0.000,02 \mathrm{mg}$ in $0.1 \mathrm{cc}{ }^{* *}$

(ii) SOT (=The clear fluid left after removal of tubercle bacilli grown on the Sauton's; medium was evaporated until reduced to one-fifth of its original volume.)

$0.5 \mathrm{cc}$ of the SOT was diluted with $4.5 \mathrm{cc}$ of sterile $0.85 \% \mathrm{NaCl}$ solution. (Thus, $0.1 \mathrm{cc}$

* For convenience, the abbreviated nomenclature, O.A.-Azo-T. "S", is occasionally employed to denote " 0 -aminophenol azo-tuberculin derived from the Sauton's synthetic-medium Old Tuberculin".

* We have chosen to report O.A.-Azo-T. "S" dosage as the actual amount of the preparation in $\mathrm{mg}$ contained in the $0.1 \mathrm{cc}$ of solution received into the skin. 
of this solution contains $0.01 \mathrm{cc}(=10$ " $\mathrm{mg}$ "*) of SOT.) This original solution was diluted serially, i.e., 1 " $\mathrm{ng}$ " in $0.1 \mathrm{cc}, 0.1$ " $\mathrm{mg}$ " in $0.1 \mathrm{cc}, 0.05$ " $\mathrm{mg}$ " in $0.1 \mathrm{cc}$ and 0.02 " $\mathrm{mg}$ " in $0.1 \mathrm{cc} . *$

2) Animals :

- Guinea-pigs were infected (subcutaneously in the inner side of the left thigh) 4 weeks previously with $1 \mathrm{mg}$ of human type of tubercle bacillus, strain $\mathrm{H}_{2}$.

3) Injection of tuberculin:

The two tuberculins under comparison, O.A.-Azo-T. "S" and SOT, were injected intracutaneously into corresponding regions of the opposite fanks of tuberculous guinea-pig. On the other hand, control animal (non-tuberculous) received the following amounts of the two tuberculins, i.e., $0.1 \mathrm{mg}$ of O A.-Azo-T. "S" and 10 " $\mathrm{mg}$ " of SOT.

4) Reading the results :

Readings were made 24,48 and 72 hours after injection. The figures were millimeter measurements of reaction (redness and induration of the skin).

\section{Results}

The results of this test are summarized in Table 2.

1) O.A.-azo-tuberculin preparations, Nos. II, III, IV, V and VI, all were found to have approximately equal potency in eliciting the specific skin reaction in tuberculous guinea-pigs; a dose of $0.01 \mathrm{mg}$ of the O.A.-azo-tuberculin preparations gave a definite positive skin reaction, and a dose of $0.000,1 \mathrm{mg}$ a well marked redness at the site of injection.

2) In the normal animals, even when such a large dose as $0.1 \mathrm{mg}$ was injected none of the above-mentioned O.A.-azo-tuberculin preparations caused and appreciable redness at the site of injection.

3) It is clear from the figures that the doses from $0.001 \mathrm{mg}$ to $0.000,1 \mathrm{mg}$ of the O.A -azo-tuberculin preparations, Nos. II to VI, are equivalent in skin-reacting potency to 0.1 " $\mathrm{mg}$ " SOT. $* * *$

4) In regard to the type of skin reaction, it may at least be said that there could not be observed any distinction between the II-, III-, IV-, V- and VIpreparations, and the SOT.

B. Experiments with Residual Parts.

Six residual parts are also tested for their skin-reacting potency, controlling. with the original SOT.

\section{Methods}

1) Substance used:

(i) The residual parts, Nos. I, II, III, IV, V and VI.

(ii) SOT.

The sample to be tested was diluted with sterile salt solution serially, i. e., $0.01 \mathrm{cc}$ in

* In this experiment, the figures " $\mathrm{mg}$ " given for SOT indicate the amount of original SOT in $\mathrm{mm}^{3}$ contained in the $0.1 \mathrm{cc}$ of solution received into the skin.

* The activity of O.A.-Azo-T. "S" on adults was investigated by Prof. Dr. M. Kakishita and his co-workers who stated that $0.000,05 \mathrm{mg}$ of O.A.-Azo-T. "S" is equivalent in skin-reacting potency to 0.05 " $\mathrm{mg} "(=0.1 \mathrm{cc}$ of $1 / 2,000)$ Koch's Old Tuberculin. 
$0.1 \mathrm{cc}, 0.001 \mathrm{cc}$ in $0.1 \mathrm{cc}$ and $0.000,1 \mathrm{cc}$ in $0.1 \mathrm{cc}$.

2) Animals :

Guinea-pigs were infected 4 weeks previously with $1 \mathrm{mg}$ of human type of tubercle bacillus, strain $\mathrm{H}_{2}$.

3) Injection of tuberculin:

The two tuberculins under comparison, residual part and SOT, were injected intracutaneously into corresponding regions of the opposite flanks. Control animal (non-tuberculous) received $0.01 \mathrm{cc}$ of a residual part and $0.01 \mathrm{cc}$ of SOT.

3) Reading the results:

Readings were made 24,48 and 72 hours after injection.

\section{Results}

This group of tests are shown in Table 3 . The significant results were as follows :

No. I-, No. II- and No. III-residual parts were of approximately equal strength which may be compared with the potency possessed by the original SOT, but both the residual parts, Nos. IV and V, compared with the above-mentioned three parts were very weak, causing a weak reaction in the most sensitive guinea-pig. The residual part VI was found to have lost its skin-reacting activity completely.

It will be noted from this and the above-mentioned experiments that the skinreaction producing activity of the residual parts is in inverse proportion to the quantity of $o$-aminophenol used for azotization of the original SOT.

\section{Lethal Test.}

The results summarized in the Tables 4 and 5 include those secured with the O.A.azo-tuberculin preparations, Nos. III to V, the residual parts, Nos. II to VI, and the SOT.

It will be noted from these experiments that intraperitoneally in a salt solution of the O.A.-azo-tuberculin preparations under consideration the minimal lethal dose for tuberculous guinea-pigs (250 270 $\mathrm{g}$ of body weight) seems to be laid between 3 and $5 \mathrm{mg}$, and that a dose of $2 \mathrm{cc}$ of the II-, III- and IV-residual parts on the other hand was found to be the minimal lethal dose, whereas a $2 \mathrm{cc}$ dose of the V-and VIresidual parts not lethal to tuberculous animals. The original SOT caused death of tuberculous animals when injected intraperitoneally even in doses of 0.2 to $0.5 \mathrm{cc}$.

Thus, as contrasted with our first report (1), the O.A.-azo-tuberculin derived from the Sauton's synthetic-medium Old Tuberculin appeared to show a general toxicity for tuberculous guinea-pigs to a slightly greater degree than did the O.A.-azo-tuberculin derived from the Maschmann's purified tuberculin; this might be owing to the contamination of the derivatives used in our later experiment.

Whether the biological properties of the $o$-aminophenol azo-tuberculin derivatives ("S") are due to one or to two substances has not yet been conclusively proved, but, from our works, it may, at least, be said that the active principle of tuberculin appears to be transformed into the easily precipitable $o$-aminophenol azo-derivative 
without being impaired its original activity.

\section{CONCLUSIONS}

1. A very simplified method is described whereby $o$-aminophenol azo-tuberculin derivative may be prepared from the concentrates of the clear fluid left after removal of tubercle bacilli grown on the Sauton's synthetic medium with $o$-aminophenol diazonium chloride.

2. This work demonstrates that the $o$-aminophenol azo-tuberculin derived from the Sauton's synthetic-medium Old Tuberculin are very active in skin test for tuberculous guinea-pig.

3. In normal guinea-pig, the derivative causes no skin reaction.

The authors are greatly indebted to Prof. Dr. H. Okamoto for helpful suggestions and advices.

\section{REFERENCES}

1) Ito, R. and Koshimura, S.: Experimental study on the influence of azo-tuberculin upon guineapigs infected with tubercle bacilli (Preliminary report). Jap. Med. J., 1, 427, 1948.

[cf. Ito, R., Koshimura, S. and Fujita, S.: On the hemolytic action of $o$-aminophenol azoprotein derivacives. Jap. Med. J., 2, 130, 194.9.] 
Table 2. Comparative skin tests with O.A.-azo-tuberculin derivatives and SOT.

\begin{tabular}{|c|c|c|c|c|c|c|c|c|c|c|c|}
\hline \multicolumn{3}{|c|}{ Guinea-pig } & \multicolumn{5}{|c|}{ O.A.-azo-tuberculin } & \multicolumn{4}{|c|}{ SOT } \\
\hline \multirow{2}{*}{\multicolumn{2}{|c|}{ No. }} & \multirow{2}{*}{$\begin{array}{l}\text { Body } \\
\text { weight } \\
\text { (g) }\end{array}$} & \multirow{2}{*}{ 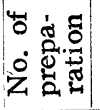 } & \multirow{2}{*}{$\begin{array}{l}\text { Dose } \\
\text { (mg) }\end{array}$} & \multicolumn{3}{|c|}{ Results taken after } & \multirow{2}{*}{$\begin{array}{c}\text { Dose } \\
\text { ("mg") }\end{array}$} & \multicolumn{3}{|c|}{ Results taken after } \\
\hline & & & & & $24 \mathrm{hr}$. & $48 \mathrm{hr}$. & $72 \mathrm{hr}$ & & $24 \mathrm{hr}$. & $48 \mathrm{hr}$ & 72 hr. \\
\hline \multirow{3}{*}{ 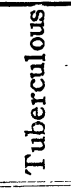 } & 150 & 320 & \multirow{4}{*}{ II } & 0.01 & $18 \times 20$ & $\begin{array}{c}15 \times 16 \\
\text { (h) }\end{array}$ & $\begin{array}{c}8 \times 10 \\
(\mathrm{~h})\end{array}$ & 10.0 & $20 \times 21$ & $\begin{array}{c}16 \times 17 \\
(\mathrm{~h})\end{array}$ & $\begin{array}{c}15 \times 16 \\
(\mathrm{~h})\end{array}$ \\
\hline & 151 & 370 & & 0.001 & $17 \times 18$ & $14 \times 17$ & $12 \times 14$ & 1.0 & $18 \times 20$ & $17 \times 19$ & $13 \times 16$ \\
\hline & 152 & 335 & & $0.000,1$ & $11 \times 12$ & $7 \times 8$ & $2 \times 2$ & 0.1 & $14 \times 15$ & $8 \times 9$ & $2 \times 3$ \\
\hline \multicolumn{2}{|c|}{$\begin{array}{l}\text { Non-cuber- } \\
\text { culous }\end{array}$} & 430 & & 0.1 & - & - & - & 10.0 & - & - & - \\
\hline \multirow{5}{*}{ 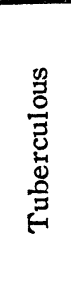 } & 153 & 330 & \multirow{6}{*}{ 固 } & 0.01 & $\begin{array}{c}30 \times 30 \\
(\mathrm{~h})\end{array}$ & $\begin{array}{c}32 \times 35 \\
(\mathrm{n}) \\
\end{array}$ & $\begin{array}{c}20 \times 22 \\
(n)\end{array}$ & 10.0 & $\begin{array}{c}30 \times 30 \\
(\mathrm{~h})\end{array}$ & $\begin{array}{c}30 \times 34 \\
(\mathrm{n})\end{array}$ & $\begin{array}{l}30 \times 30 \\
-(n) \\
\end{array}$ \\
\hline & 154 & 345 & & 0001 & $\begin{array}{c}10 \times 14 \\
\text { (h) }\end{array}$ & $\begin{array}{l}9 \times 10 \\
(\mathrm{~h})\end{array}$ & $\begin{array}{c}7 \times 12 \\
(\mathrm{n})\end{array}$ & 1.0 & $\begin{array}{c}13 \times 16 \\
(\mathrm{~h})\end{array}$ & $\begin{array}{c}17 \times 17 \\
(\mathrm{~b})\end{array}$ & $\begin{array}{c}12 \times 14 \\
(\mathrm{n})\end{array}$ \\
\hline & 155 & 280 & & $0.000,1$ & $11 \times 12$ & $8 \times 9$ & $5 \times 6$ & 0.1 & $15 \times 20$ & $10 \times 10$ & $10 \times 10$ \\
\hline & 156 & 330 & & $0.000,05$ & $8 \times 10$ & $2 \times 4$ & - & 0.05 & $11 \times 15$ & $5 \times 6$ & $\longrightarrow$ \\
\hline & 157 & 340 & & $0.000,02$ & $11 \times 11$ & $3 \times 3$ & - & 0.02 & $15 \times 15$ & $9 \times 9$ & - \\
\hline \multicolumn{2}{|c|}{$\begin{array}{c}\text { Non-tuber- } \\
\text { culous }\end{array}$} & 430 & & 0.1 & - & $\longrightarrow$ & - & 10.0 & & . & - \\
\hline \multirow{3}{*}{ 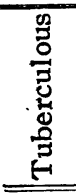 } & 158 & 375 & \multirow{4}{*}{ IV } & 0.01 & $23 \times 25$ & $18 \times 20$ & $18 \times 20$ & 10.1 & $24 \times 25$ & $20 \times 20$ & $18 \times 19$ \\
\hline & 159 & 320 & & 0.001 & $12 \times 12$ & $8 \times 9$ & $7 \times 7$ & 1.0 & $12 \times 14$ & $11 \times 12$ & $3 \times 4$ \\
\hline & 160 & 34.0 & & $0.000,1$ & $13 \times 16$ & $8 \times 9$ & $6 \times 7$ & 0.1 & $23 \times 26$ & $12 \times 14$ & $10 \times 10$ \\
\hline \multicolumn{2}{|c|}{$\begin{array}{l}\text { Non-tuber- } \\
\text { culous }\end{array}$} & 375 & & 0.1 & 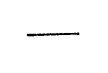 & 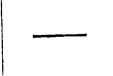 & - & 10.0 & & & . \\
\hline \multirow{3}{*}{ 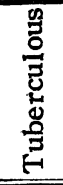 } & 161 & 420 & \multirow{4}{*}{$\nabla$} & 0.01 & $10 \times 11$ & $12 \times 12$ & $2 \times 2$ & 10.0 & $14 \times 16$ & $14 \times 17$ & $2 \times 3$ \\
\hline & 162 & 460 & & 0.001 & $11 \times 12$ & $12 \times 13$ & $6 \times 6$ & 1.0 & $15 \times 17$ & $16 \times 17$ & $9 \times 10$ \\
\hline & 163 & 305 & & $0.000,1$ & $14 \times 14$ & $9 \times 9$ & $2 \times 2$ & 0.1 & $16 \times 18$ & $12 \times 15$ & $11 \times 12$ \\
\hline \multicolumn{2}{|c|}{$\begin{array}{c}\text { Non-tuber- } \\
\text { culous }\end{array}$} & 350 & & 0.1 & - & & & 10.0 & & & $\dot{-}$ \\
\hline \multirow{3}{*}{ 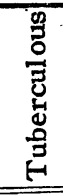 } & 164 & 300 & \multirow{4}{*}{ VI } & 0.01 & $\begin{array}{c}35 \times 35 \\
\text { (h) }\end{array}$ & $\begin{array}{c}25 \times 35 \\
(n)\end{array}$ & $\begin{array}{c}20 \times 25 \\
(n) \\
\end{array}$ & 10.0 & $\begin{array}{c}28 \times 30 \\
\text { (h) }\end{array}$ & $\begin{array}{c}33 \times 34 \\
\text { (n) }\end{array}$ & $\begin{array}{c}24 \times 25 \\
(n)\end{array}$ \\
\hline & 165 & 340 & & 0.001 & $10 \times 10$ & $4 \times 5$ & $4 \times 5$ & 1.0 & $12 \times 16$ & $11 \times 14$ & $7 \times 9$ \\
\hline & 166 & 315 & & $0.000,1$ & $1.2 \times 13$ & $5 \times 8$ & $2 \times 3$ & 0.1 & $16 \times 20$ & $10 \times 11$ & $3 \times 4$ \\
\hline \multicolumn{2}{|c|}{$\begin{array}{l}\text { Non-tuber- } \\
\text { culous }\end{array}$} & 375 & & 0.1 & $\longrightarrow$ & & & 10.0 & & & \\
\hline
\end{tabular}

Remarks: (h) = Ecchymosis, $(\mathfrak{n})=$ Necrosis.

$18 \times 20=$ Diameters of redness and induration in $\mathrm{mm}$.

$-=$ No trace of redness of induration at the site of injection. 
Table 3. Comparative skin tests with the residual parts and SOT.

\begin{tabular}{|c|c|c|c|c|c|c|c|c|c|c|c|}
\hline \multicolumn{3}{|c|}{ Guinea-pig } & \multicolumn{5}{|c|}{ Residual part } & \multicolumn{4}{|c|}{ SO'T } \\
\hline \multirow{2}{*}{\multicolumn{2}{|c|}{ No. }} & \multirow{2}{*}{$\begin{array}{c}\text { Body } \\
\text { weight } \\
\text { (g) }\end{array}$} & \multirow{2}{*}{ No. } & \multirow{2}{*}{$\begin{array}{l}\text { Dose } \\
\text { (cc) }\end{array}$} & \multicolumn{3}{|c|}{ Results taken after } & \multirow{2}{*}{$\begin{array}{l}\text { Dose } \\
(\mathrm{cc})\end{array}$} & \multicolumn{3}{|c|}{ Results taken after } \\
\hline & & & & & $24 \mathrm{hr}$. & $48 \mathrm{hr}$. & $72 \mathrm{hr}$. & & $24 \mathrm{hr}$. & $48 \mathrm{hr}$. & $72 \mathrm{hr}$. \\
\hline \multirow{3}{*}{ 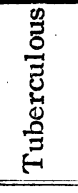 } & 170 & 350 & \multirow{4}{*}{1} & 0.01 & $14 \times 16$ & $11 \times 12$ & - & $0: 01$ & $16 \times 16$ & $14 \times 14$ & - \\
\hline & 171 & 425 & & 0.001 & $19 \times 20$ & $25 \times 25$ & $17 \times 22$ & 0.001 & $18 \times 22$ & $25 \times 26$ & $22 \times 22$ \\
\hline & 172 & 400 & & $0.000,1$ & $10 \times 12$ & $10 \times 10$ & - & $0.000,1$ & $12 \times 15$ & $10 \times 10$ & - \\
\hline \multicolumn{2}{|c|}{$\begin{array}{l}\text { Non-tuber- } \\
\text { culous }\end{array}$} & 370 & & 0.01 & - & $\longrightarrow$ & $\longrightarrow$ & 0.01 & - & - & $\longrightarrow$ \\
\hline$\stackrel{0}{0}$ & 173 & 355 & \multirow{4}{*}{$\mathbb{I}$} & 0.01 & $22 \times 22$ & $\begin{array}{c}21 \times 26 \\
(\mathrm{~h}) \\
\end{array}$ & $\begin{array}{l}11 \times 12 \\
\text { (h) }\end{array}$ & 0.01 & $22 \times 27$ & $\begin{array}{c}23 \times 26 \\
(\mathrm{~h})\end{array}$ & $\begin{array}{l}14 \times 16 \\
\text { (b) }\end{array}$ \\
\hline . & 174 & 440 & & 0.001 & $16 \times 18$ & $14 \times 16$ & $7 \times 9$ & 0.001 & $\begin{array}{c}24 \times 30 \\
\text { (h) }\end{array}$ & $\begin{array}{c}20 \times 20 \\
(\mathrm{~h})\end{array}$ & $\begin{array}{c}10 \times 10 \\
\text { (h) }\end{array}$ \\
\hline 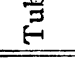 & 175 & 465 & & $0.000,1$ & $19 \times 22$ & $12 \times 14$ & - & $0.000,1$ & $22 \times 26$ & $18 \times 19$ & $4 \times 4$ \\
\hline \multicolumn{2}{|c|}{$\begin{array}{c}\begin{array}{c}\text { Non-tuber- } \\
\text { culous }\end{array} \\
\end{array}$} & 370 & & 0.01 & - & - & - & 0.01 & - & - & $\longrightarrow$ \\
\hline$\stackrel{\infty}{0}$ & 176 & 390 & \multirow{4}{*}{ II } & 0.01 & $22 \times 25$ & $17 \times 18$ & $12 \times 16$ & 0.01 & $20 \times 22$ & $22 \times 22$ & $18 \times 22$ \\
\hline 己્. & 177 & 65 & & 0.001 & $16 \times 16$ & $14 \times 14$ & $13 \times 14$ & 0.001 & $15 \times 20$ & $14 \times 16$ & $14 \times 14$ \\
\hline $\overrightarrow{3}$ & 178 & 370 & & $0.000,1$ & $13 \times 16$ & $10 \times 14$ & $4 \times 4$ & $0.000,1$ & $13 \times 14$ & $10 \times 15$ & $12 \times 13$ \\
\hline \multicolumn{2}{|c|}{$\begin{array}{c}\text { Non-tuber- } \\
\text { culous }\end{array}$} & 340 & & 0.01 & - & $\longrightarrow$ & - & 0.01 & - & - & - \\
\hline \multirow{3}{*}{ 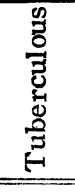 } & 379 & 320 & \multirow{4}{*}{ IV } & 0.01 & $11 \times 12$ & $7 \times 9$ & - & 0.01 & $12 \times 14$ & $12 \times 15$ & $10 \times 14$ \\
\hline & 180 & 345 & & 0.001 & $13 \times 14$ & $12 \times 14$ & $3 \times 4$ & 0.001 & $22 \times 24$ & $\begin{array}{c}20 \times 24 \\
(\mathrm{~h})\end{array}$ & $\begin{array}{l}12 \times 14 \\
\text { (h) }\end{array}$ \\
\hline & 181 & 370 & & $0.000,1$ & - & $\longrightarrow$ & - & $0.000,1$ & $14 \times 17$ & $10 \times 11$ & $2 \times 3$ \\
\hline \multicolumn{2}{|c|}{$\begin{array}{c}\text { Non-tuber- } \\
\text { culous }\end{array}$} & 480 & & 0.01 & - & 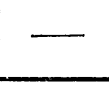 & - & 0.01 & - & - & 一 \\
\hline \multirow{3}{*}{ 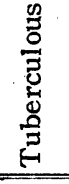 } & 182 & $3 c 5$ & & 0.01 & $3 \times 4$ & - & - & 0.01 & $12 \times 14$ & $13 \times 14$ & $5 \times 7$ \\
\hline & 183 & 390 & & 0.001 & $\bar{z}$ & $\longrightarrow$ & - & 0.001 & $17 \times 20$ & $15 \times 15$ & $12 \times 13$ \\
\hline & 184 & 410 & & $0.000,1$ & $5 \times 7$ & $2 \times 2$ & - & $0.000,1$ & $22 \times 24$ & $12 \times 13$ & $11 \times 12$ \\
\hline \multicolumn{2}{|c|}{$\begin{array}{c}\text { Non-tuber- } \\
\text { culous }\end{array}$} & 350 & & 0.01 & - & - & - & 0.01 & - & $\longrightarrow$ & - \\
\hline \multirow{3}{*}{ 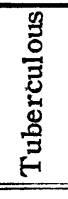 } & 185 & 340 & \multirow{4}{*}{ VI } & 0.01 & - & - & - & 0.01 & $\begin{array}{c}18 \times 20 \\
(\mathrm{~h})\end{array}$ & $\begin{array}{c}22 \times 24 \\
(\mathrm{n})\end{array}$ & $\begin{array}{l}14 \times 15 \\
\text { (n) }\end{array}$ \\
\hline & 186 & 330 & & 0.001 & - & - & - & 0.001 & $\begin{array}{c}13 \times 18 \\
\text { (h) }\end{array}$ & $\begin{array}{c}24 \times 25 \\
\text { (h) } \\
\end{array}$ & $\begin{array}{c}12 \times 13 \\
(\mathrm{n}) \\
\end{array}$ \\
\hline & 187 & 320 & & $0.000,1$ & - & - & - & 0000,1 & $10 \times 12$ & $7 \times 9$ & $2 \times 3$ \\
\hline \multicolumn{2}{|c|}{$\begin{array}{l}\text { Non-tuber- } \\
\text { culous }\end{array}$} & 430 & & 0.01 & 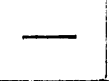 & - & - & 0.01 & - & - & - \\
\hline
\end{tabular}

See remarks of Table 2. 
Table 4. Lethal tests with O.A.-azo-tuberculin derivative.

1) Substance used: O.A.-azo-tuberculin preparations, Nos. III, IV, V and VI.

$20.0 \mathrm{mg}$ of O.A.-Azo-T. " $\mathrm{S}$ " to be tested was dissolved in $10.0 \mathrm{cc}$ of sterile salt solution with the aid of a little $\mathrm{N} / 10 \mathrm{NaOH}$.

Thus, $1.0 \mathrm{cc}$ of this, solution contains $2.0 \mathrm{mg}$ of O.A.-Azo-T. "S".

2) Animals: Guinea-pigs were infected 6 weeks previously with $1 \mathrm{mg}$ of human type of tubercle bacillus, strain $\mathrm{H}_{2}$.

3) Injection of substance: Intraperitoneally.

\begin{tabular}{|c|c|c|c|c|}
\hline \multicolumn{2}{|c|}{ O.A.-azo-tuberculin } & \multicolumn{2}{|c|}{ Tuberculous guinea-pig } & \multirow{2}{*}{ Results } \\
\hline $\begin{array}{l}\text { No. of } \\
\text { preparation }\end{array}$ & Dose (mg) & No. & $\begin{array}{l}\text { Body weight } \\
\text { (g) }\end{array}$ & \\
\hline \multirow{4}{*}{ III } & 5 & 251 & 310 & $D_{t}$ \\
\hline & 4 & 252 & 355 & $\mathrm{D}_{t}$ \\
\hline & \multirow{2}{*}{2} & 253 & 420 & $\mathrm{~L}$ \\
\hline & & 254 & 400 & $\mathrm{~L}$ \\
\hline \multirow{3}{*}{ IV } & \multirow{2}{*}{10} & 255 & 310 & $\mathrm{D}_{5}$ \\
\hline & & 256 & 410 & $\mathrm{D}_{<24}$ \\
\hline & 5 & 257 & 330 & $\mathrm{D}_{5}$ \\
\hline \multirow{6}{*}{$\nabla$} & \multirow{2}{*}{10} & 258 & 350 & $\mathrm{D}_{5}$ \\
\hline & & 259 & 340 & $\mathrm{D}_{4}$ \\
\hline & \multirow{2}{*}{5} & 260 & 420 & $\mathrm{D}_{5}$ \\
\hline & & 261 & 380 & L \\
\hline & \multirow{2}{*}{2} & 262 & 290 & $\mathrm{~L}$ \\
\hline & & 263 & 235 & $\mathrm{D}_{<31}$ \\
\hline \multirow{4}{*}{ VI } & \multirow{2}{*}{10} & 264 & 340 & $D_{5}$ \\
\hline & & 265 & 370 & $\mathrm{D}_{5}$ \\
\hline & \multirow{2}{*}{2} & 266 & 345 & $\mathrm{~L}$ \\
\hline & & 267 & 320 & $\mathrm{~L}$ \\
\hline
\end{tabular}

Remarks: $\mathrm{D}_{4}=$ Died in 4 hours, $\mathrm{D}_{<24}=$ Died within 24 hours. $L=$ Lived. 
Table 5. Lethal tests with residual part and SOT.

1) Substance used:

a) The residual parts, Nos. II, III, IV, V and VI.

b) SOT.

2) Animals: Guinea-pigs were infected 6 weeks previously with $1 \mathrm{mg}$ of human type of tubercle bacillus, strain $\mathrm{H}_{2}$.

3) Injection of substance: Intraperitoneally.

\begin{tabular}{|c|c|c|c|c|c|}
\hline \multicolumn{2}{|c|}{$\begin{array}{c}\text { Substance } \\
\text { tested }\end{array}$} & \multirow{2}{*}{ Dose (cc) } & \multicolumn{2}{|c|}{ Tuberculous guinea-pig } & \multirow{2}{*}{ Results } \\
\hline \multirow{13}{*}{ 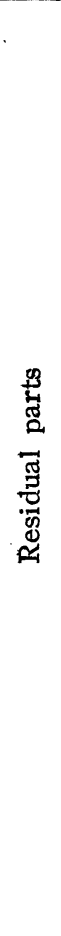 } & No. & & No. & $\begin{array}{c}\text { Body weight } \\
(\mathrm{g})\end{array}$ & \\
\hline & \multirow{4}{*}{ II } & \multirow{2}{*}{2} & 268 & 305 & $\mathrm{D}_{9}$ \\
\hline & & & 269 & 350 & $\mathrm{~L}$ \\
\hline & & \multirow{2}{*}{1} & 270 & 300 & $\mathrm{D}_{6}$ \\
\hline & & & 271 & 295 & $\mathrm{D}_{6}$ \\
\hline & \multirow{2}{*}{ 直 } & \multirow{2}{*}{2} & 272 & 315 & L \\
\hline & & & 273 & 320 & $\mathrm{D}_{\mathrm{8}}$ \\
\hline & \multirow{2}{*}{ IV } & \multirow{2}{*}{2} & 274 & 300 & $\mathrm{D}_{<24}$ \\
\hline & & & 275 & 330 & $\mathrm{D}_{<24}$ \\
\hline & \multirow{2}{*}{$\mathrm{V}$} & \multirow{2}{*}{2} & 276 & 330 & L \\
\hline & & & 277 & 325 & L \\
\hline & \multirow{2}{*}{ II } & \multirow{2}{*}{2} & 278 . & 375 & $\mathrm{~L}$ \\
\hline & & & 279 & 305 & $\mathrm{~L}$ \\
\hline & \multirow{6}{*}{$\mathrm{T}$} & \multirow{2}{*}{1} & 286 & 350 & $D_{<24}$ \\
\hline & & & 287 & 330 & $\mathrm{D}_{<24}$ \\
\hline & & \multirow{2}{*}{0.5} & $\quad 288$ & 440 & $\mathrm{D}_{<24}$ \\
\hline & & & 289 & 405 & $D_{<24}$ \\
\hline & & \multirow{2}{*}{0.2} & 292 & 365 & $\mathrm{D}_{<24}$ \\
\hline & & & 293 & 310 & L \\
\hline
\end{tabular}

See remarks of Table 4. 